\title{
A Comparison of the Influence of Personal and Cultural Values on the Consumption of Luxury Goods across Arab Regions: Levant versus Gulf
}

\author{
Maya F. Farah \\ Lebanese American University \\ E-Mail: mfarah@lau.edu.lb \\ Rayan S. Fawaz \\ Lebanese American University \\ E-Mail: rayan.fawaz01@lau.edu
}

\begin{abstract}
Consumption patterns across different cultures are influenced by several factors, including personal and cultural ones. Collectivist cultures play a major role in the consumption decision-making process that an individual goes through, as culture typically affects consumers' taste orientation, specifically toward luxury goods. The main motivation behind this study is to investigate the influence of two major collectivist cultural values - namely, face saving and group orientation-on the perception and consumption of luxury goods across two Arab market regions (i.e., the Levant versus the Gulf). A survey was completed by 400 consumers sampled from different universities in the capitals of Lebanon, Jordan, Qatar, and Oman. The results indicate that not all luxury-related factors influence face saving in the Levant and Gulf regions. In addition, no such factors influence group orientation in either region. Beliefs such as the assumption that group orientation plays a significant role in consumers' decision making and that hedonism is not appreciated in Arab cultures are challenged, which indicate slow changes in the Arab cultures. These findings are useful to marketers who aim to promote luxury products in the Arab world as they provide a greater understanding of consumers' perceptions of such products.
\end{abstract}

Keywords: Luxury Consumption, Personal Values, Cultural Values, Conspicuous Consumption, Arab Consumers 


\section{INTRODUCTION}

Culture, as a dynamic process, assumes that cultural differences instigate distinctions in consumer behavior within and across national borders (Miller, 1995). In light of the growth in the luxury market and the ease of accessibility to luxury products to a broader proportion of consumers, consumer behavior is no longer unexpectedly altered when national borders are crossed (Farley \& Lehmann, 1994).

Collectivist cultures play a major role in an individual's life, consumption decision making and patterns, and taste orientation toward luxury goods. The world market for luxury goods has experienced a remarkable boom. Indeed, from being valued at $\$ 60$ billion in 1990, it is expected to be worth over $\$ 240$ billion by 2015 (Dubois \& Duquesne, 1993); this growth could be explained by the fact that consumption has become "a means of self-realization and identification, as consumers no longer merely consume products; they consume the symbolic meaning of those products, the image" (Chaudhuri \& Majumdar, 2006). Luxury consumption is a field of particular interest to the Arab world, which has a population of 422 million people sharing the same language, a dominant religion (i.e., Islam), a broad variety of cultural similarities, and a remarkable reserve of natural resources. In addition to common cultural similarities, the latter factors make this region a very lucrative market for luxury brands (World Arabic Language Day, 2012).

Wiedmann, Hennigs, and Siebels (2009) believe that people's cultural values shape what is considered significant to them and can often affect their perceptions of luxury. Engel, Blackwell, and Miniard (1990) define culture as "the set of values, ideas, artefacts and other meaningful symbols that help individuals to communicate, interpret and evaluate as members of society." Cultures are categorized into two main groups: collectivist versus individualistic (Hosfstede, 1980). The Arab region has been known for being a highly collectivist society, where norms and values are usually passed down over generations, consequently affecting consumer behavior (Barakat, 1993).

Luxury goods have diverse characterizations, including quality, hedonism, and conspicuousness (Vigneron \& Johnson, 2004). Seringhaus (2002) explains that a luxury product is recognized based on the exceptional labor and skills required and the expected outstanding quality of its raw materials, which give a brand its identification as premium. Status goods are defined as items for which "the mere use or display of a particular branded product brings prestige to the owner, apart from any functional utility" (Husic \& Cicic, 2009). According to the theory of impression management, consumers are greatly influenced by the internal urge to create a desirable social image through their hedonistic purchase behavior (Sallot, 2002). Indeed, luxury- 
driven consumption is meant to improve one's social status and personal image; this is an outcome particularly sought by Arab consumers, for whom status is of noteworthy relevance (Riquelme, Rios, \& Al-Sharhan, 2011). Veblen (1899) initially described the latter type of consumption as the "ostentatious use of goods or services to signal status to other members of a society." However, some debate still surrounds Veblen's theory as researchers such as Acikalin, Gul, and Develioglu (2009) argue that conspicuous consumption is not limited to consumers from upper and elite classes.

Furthermore, a number of sociological studies have jointly tackled the concepts of face saving and group orientation in the area of luxury consumption (e.g., Jin \& Kang, 2011). The Confucian principle of "face" pertains to sustaining one's public dignity and standing (Lee, 1990). To gain face, one has to put considerable effort into winning the approval of others in the group, especially in collectivist societies (Triandis, 1995). Indeed, relying on the group equips the individual with a feeling of safety, along with securing a "collective identity" (Abosag \& Farah, 2014). Accordingly, this study aims to investigate the influence of the aforementioned two major collectivist cultural values (i.e., face saving and group orientation) on the perception and consumption of luxury goods across the two main Arab market regions: the Levant versus the Gulf. In fact, exploring these influences on Arab consumers will enhance the understanding of such intricate subcultures. Despite the increased attention toward this emerging market, no prior study has empirically investigated Arab consumers' perceptions of luxury goods as a result of the influence of these specific cultural values. Hence, this research aims not only to bridge the gap in the literature by empirically testing a related framework across four countries in this under-researched region, but also to assist marketers who intend to promote luxury products in such cultures, by providing them with a greater understanding of how their consumers perceive luxury products.

\section{LITERATURE REVIEW}

\section{Personal Influence}

Although the same luxury item consumed by various individuals within a society may have different meanings to each person, luxury brands may be imperative to consumers who look for social status, image, and means to enhance their ranking in a society through specific patterns of conspicuous consumption (Wiedmann et al., 2009). In cultures where success is measured largely based on one's financial situation, the consumption of luxury goods is often influential in assigning each individual's "place" in a society. Moreover, luxury goods often provide a path for people to buy into a standard of living associated with the "haute bourgeoisie of 
society" (Asia Market Intelligence, 2003; Park, Rabolt, \& Jeon, 2008). In the nineteenth century, Veblen (1899) recognized a social switch by which "leisure class consumers have turned to luxury products, which could be used to signify wealth and status, while distancing conspicuous consumers from more humble, ancestral beginnings" (p. 55). According to Bagwell and Bemheim (1996), consuming luxury brands is a means to attain higher social status rather than physiological and utilitarian benefits. Along these lines, Kapferer and Bastien (2009) consider that "the DNA of luxury is the symbolic desire to belong to a superior class," showcasing that luxury is often considered by consumers as a social maker. In particular, the relatively recent economic boom witnessed by a number of Arab countries as a result of their natural resources excavations (Vel, Captain, Al Abbas, \& Al Hashemi, 2011) appears to be an instigator of the increase in luxury demand.

\section{Culture and Luxury Consumption}

Luxury is a key aspect that distinguishes a brand in a product category (Kapferer, 1997) and an essential force directing consumers' preferences and usages (Dubois \& Duquesne, 1993). The consumption of luxury goods is a practice that spans across geographical and cultural boundaries, with the latter being consistent among cultures in the Arab region, where consumers fancy exhibiting their possessions as evidence of their social standing (Belk, 1988). Culture has long been linked to human behavior as actions are usually believed to reflect their cultural value system (Teimourpour \& Hanzaee, 2011). Indeed purchase choices at times seem to be made by the group rather than by the individual (Kabaskal \& Bodur, 2002).

\section{Cultural Influence of Collectivist Values}

Hosfstede's (1980) landmark model on the dimensions of culture differentiates cultures according to five dimensions, one of which distinguishes between collectivist and individualistic cultures. In individualist societies, ties between individuals are often loose, and everyone is likely to look after personal interests. On the other hand, collectivist cultures are "societies in which people from birth onwards are integrated into strong, cohesive in-groups, often extended families, which continue to provide protection in exchange for unquestioning loyalty" (Teimourpour \& Hanzaee, 2011). People from collectivist cultures highly regard interdependence (Hui \& Triandis, 1986) and are usually more concerned about doing the right thing and acting suitably than doing what they personally would like to do (Triandis, 1995). A familiar trait of individuals within these cultures is the concern to acquire the approval of their group; failing to do so initiates distressing feelings of shame (Hui \& Triandis, 1986). 
In Arab cultures, individuals exhibit an "affiliation-oriented nature" whereby family and group values and collective interests are set as a priority compared to one's private life. As Hofstede (1991) suggests, Arab societies are more inclined to embrace group rather than individual decision making; "group harmony, consensus, and cooperation" are often preferred over individual initiative (Dirani, 2008). In Lebanon, individuals feel a stronger need to conform to their local social groups' expectations than to the broader national group requisites (Farah \& Newman, 2010). Pertaining to the Levant region, and similar to the Lebanese culture, the Jordanian culture is also assumed to be collectivist due the similarity of their social traits (Alkailani, Azzam, \& Athamneh, 2012). The Gulf Corporation Council (GCC) populations, which are collectivist as well, share similar traditions, customs, cultures, faiths, local tongues, and political structures; consequently, they may be regarded as homogenous (AtTwaijri \& Al-Muhaiza, 1996). In fact, people from the state of Qatar value cultural norms and abide closely by the influence of their extended family, which largely shapes their individual choices (Kamal, 1983). Oman, which is also part of the GCC, shares similar characteristics to those of Qatar, allowing it to be labeled as a collectivist culture as well.

\section{Face Saving and Group Orientation}

In recent times, a growing number of sociological studies have tackled the cultural values of face saving and group orientation concurrently (Jin \& Kang, 2011), which relate to the idea of self-concept-in other words, the conviction that individuals possess about their own traits and overall image (Solomon, Bamossy, Askegaard, \& Hogg, 2010). "Face" corresponds to the Chinese term indicating one's dignity based on an appropriate relationship between an individual and the group to which he or she belongs. Collectivist cultures are reputed for their individuals being face-conscious (Hofstede, 1983). Obtaining face requires rigorous effort to reach others' admiration, respect, and consequently group integration. This can be achieved, although not entirely, through the external facade of rank and prosperity (Bond, 1991).

In collectivist cultures, the interdependent self plays a crucial role for integrating the individual into the group (Monkhouse, Barnes, \& Stephan, 2011). Social identity is the individual's self-concept derived from perceived membership of social groups (Hogg \& Vaughan, 2002). Hence, conformity is looked upon as a positive attribute of collective cultures, which provides a means for maintaining social harmony. Tajfel and Turner (1986) identify three variables accountable for in-group favoritism: (a) the degree to which individuals relate to a particular group, which affects one's adherence to that group and hence one's self-concept aspect; (b) the degree to which the 
established context allows for contrast between groups; and (c) the perceived significance of the comparison group, which is altered by the status of the in-group. In these societies, a consumer's decision-making process, especially that related to luxury products, is highly shaped by the strong influence of one's family, as related choices often reflect the family's overall stand in the society (Vel et al., 2011).

The consumption of luxury products is the result of five factors. First, quality indicates what a product does and how it functions (Berthon, Pitt, \& Campbell, 2009). Gentry, Putrevu, Shultz, and Commuri (2001) found that one of the reasons consumers buy luxury brands is the superior quality mirrored by the brand name. Arab countries in particular have developed the belief that products created in the West possess a superior quality (Vel et al., 2011). Moreover, acknowledging the fact that individuals who value face-saving place bigger concern on how others see them, the quality attribute of luxury goods is regarded as significant as it plays a positive role in the way a group will view these individuals. Hence, it is likely that these consumers will opt for a product with superior quality that impresses other group members. Accordingly, we hypothesize:

$H_{1}$ : Arab consumers who highly value face-saving will have high perceptions of the quality dimension of luxury.

$\mathrm{H}_{2}$ : Arab consumers who highly value group orientation will have high perceptions of the quality dimension of luxury.

The second factor, hedonism, describes the assumed usefulness and intrinsically tempting goods acquired from the buying of lavish products to stimulate feelings and emotional states attained from personal rewards and fulfillment (Sheth, Bruce, \& Gross, 1991). The latter type of consumers seeks out the pleasurable emotion stirred by these possessions and the feeling of personal gratification and self-indulgence that they provide (Vigneron \& Johnson, 2004). Dubois (1993) argues that, although some consumer researchers have built up a hedonic lookout according to which luxury goods purchase largely satisfies a buyer's taste for symbolic meanings, others have reiterated consumers' yearnings to enhance their personality through their possessions. Consequently, assuming the collectivist nature of the Arab societies, which are supposed to be more concerned with the groups' considerations and personal image within that group than with personal interests, we hypothesize:

$H_{3}$ : Arab consumers who highly value face-saving will have low perceptions of the hedonistic dimension of luxury.

$H_{4}$ : Arab consumers that highly value group orientation will have low perceptions of the hedonistic dimension of luxury. 
The third factor behind luxury brand consumption is related to conspicuousness, which appears to be the primary drive behind such acquisitions. Conspicuousness has been defined as buying to impress others (Mason, 1992) and to provide status regardless of the consumer's earnings or social class (Belk, 1988). Displaying wealth becomes a considerably important social symbol allowing an individual to climb the social ladder (O'Cass \& Frost, 2002). In fact, although collectivist cultures focus on humility, they still encourage more sophisticated consumption if it is considered essential to one's social station (Yang, 1963). This study aims to test the positive impact of face-saving and group orientation on the conspicuous dimension of luxury in Arab cultures. Hence, we hypothesize:

$H_{5}$ : Arab consumers who highly value face-saving will have high perceptions of the conspicuous dimension of luxury.

$H_{6}$ : Arab consumers who highly value group orientation will have high perceptions of the conspicuous dimension of luxury.

Uniqueness, the fourth factor, defines how a luxury product is perceived. It is assumed that the believed exclusivity of a limited product enhances the consumer's desire or preference for a brand (Pantzalis, 1995), especially when the latter is regarded as expensive (Verhallen \& Robben, 1994). In Arab societies, where the concern is mainly geared toward group harmony and one's image and status in one's social group, we aim to test the following hypotheses concerning the importance of the uniqueness aspect:

$H_{7}$ : Arab consumers who highly value face-saving will have high perceptions of the exclusive dimension of luxury.

$H_{8}$ : Arab consumers who highly value group orientation will have high perceptions of the exclusive dimension of luxury.

Finally, the extended-self points to the social value associated with luxury (Wiedmann, Hennigs, \& Siebels, 2009), which confirms the importance of possessions and the desire to use luxury items in order to integrate symbolic meaning into a particular identity. The consumption of luxury goods, particularly in a collectivist culture, involves purchasing a product that represents value not only to the individual, but also - and more importantly - to one's reference group. Consumers may use luxury items to incorporate the associated emblematic significance into their self (Vigneron \& Johnson, 2004) or to build up and maintain their existing identity (Dittmar, 1994). In the context of the assumed collectivist Arab societies, we hypothesize that: 
$\mathrm{H}_{9}$ : Arab consumers who highly value face-saving will have high perceptions of the extended-self component of luxury.

$H_{10}$ : Arab consumers who highly value group orientation will have high perceptions of the extended-self component of luxury.

\section{METHODOLOGY}

The literature review on luxury purchasing and its different underlying causes was at the base of the proposition of the ten hypotheses to be tested in four Arab countries. A positivist approach was adopted, whereby a survey was conducted to explain the influence of both cultural and personal values on the consumption of luxury goods in the Arab world.

\section{Sampling Design and Data Collection}

Due to the exploratory nature of this study in the Arab world, the researchers opted for a non-probabilistic sampling design, based on a convenience sample. The questionnaire required around ten minutes to complete and was directed toward a number of university students, faculty, and personnel throughout Lebanon, Jordan, Qatar, and Oman. Universities were chosen to be representative of all different social classes. The choice of university students was backed by the fact that "young people have been recognized as a specialized segment of the market for a variety of products and services and their behavior as consumers has received increasing attention among marketers" (Moschis \& Moore, 1979). Moreover, according to Gunter and Furnham (1998), the purchasing power of young adults demonstrates continuous growth, which has captured the attention of marketers, manufacturers, and advertisers, encouraging them to devise effective methods to reach them.

The sample of respondents was chosen to give a general indication of luxury product purchase motives for the populations under study, allowing for a comparison between Levant and Gulf cultures. The sample size from each country was chosen to be equal given the fact that the four countries under scrutiny have similar population sizes. The population is 5,882,562 for Lebanon, 7,9300,491 for Jordan, 2,123,160 for Qatar, and finally 3,219,775 for Oman (Central Intelligence Agency, 2014).

As part of the study was conducted outside the researchers' country of residence, a group of overseers - mainly faculty members - supervised the completion of selfadministered questionnaires. Potential respondents were all assured anonymity and the confidentiality of their answers. 


\section{Instrument Description}

In order to obtain deeper insights into how cultural and personal values influence the decision to consume luxury goods in the Arab world, a quantitative survey was adopted based on a study developed by Monkhouse, Barnes, and Stephan (2011). The survey contained 38 statements reflecting the various constructs under study. The first part of the questionnaire comprised four demographic questions related to gender, age, education level, and nationality.

The second part required participants to reveal their level of agreement or disagreement on 34 items based on a 7-point Likert scale ranging from strongly disagree $(-3)$ to strongly agree $(+3)$. These scales relate to the constructs of quality, hedonism, conspicuousness, exclusivity, extended-self, face-saving, and group orientation. A list of high-end fashion brands, such as Channel No. 5 perfume, a Lacoste shirt, Gucci sunglasses, a Louis Vuitton handbag, a Rolex watch, Bang \& Olufsen Hi-Fi system, and a BMW 7-series car, was given as examples of high-end luxury brands.

Quality, the first item, was measured using the following 4-item scale after the deletion of two items for reliability purposes: luxury goods are bought for (a) their excellent quality, (b) their excellent design, and (c) their excellent customer service and (d) luxury goods are very suitable as a gift for others.

Hedonism, which indicates a person's willingness to behave in a way that brings personal pleasure, was measured using five statements: (a) luxury goods make people dream, (b) luxury goods are bought for a feeling of fulfillment, (c) luxury goods are bought for self-indulgence, (d) luxury goods bring pleasure to the owner, and (e) luxury goods bring excitement.

Conspicuousness, which describes the buying of expensive items to enhance an individual's social prestige, was tackled by six questions: (a) luxury goods should look expensive, (b) people like to buy luxury goods in prestigious shops, (c) luxury goods are bought for their distinctive brand design, (d) luxury goods should be easily recognized by others, (e) luxury goods are a symbol of high social status, and (f) luxury goods impress people.

Exclusivity, meaning that a some people prefer to buy certain items due to the fact that they will be the only ones owning them, was measured by four items: (a) it is good to be among a very few people owning a truly luxury product, (b) I would buy luxury goods to make myself stand out, (c) once a product becomes mass-produced, it is not luxurious anymore, and (d) luxury goods are bought because they are exclusive.

Extended-self, which denotes the social value associated with purchasing luxury goods, was assessed using four statements: (a) people buying luxury goods belong to 
an elite class, (b) buying luxury goods is synonymous with success, (c) buyers of luxury goods are wealthy people, and (d) buyers of luxury goods are sophisticated people.

Face-saving, which refers to preserving one's image as well as the family's image, was measured using four statements: (a) I am concerned with not bringing shame to myself, (b) I pay a lot of attention to how others see me, (c) I am concerned with protecting the pride of my family, and (d) I feel ashamed if I lose face.

Group orientation, describing how involved individuals are with their group and the importance placed on social norms, was assessed using the following statements: (a) I recognize and respect social expectations, norms, and practices; (b) when I am uncertain how to act in a social situation, I try to do the same as what others do; and (c) when I buy the same things my friends buy, I feel closer to them.

To limit validity issues, a pilot stage allowed for checking for difficult or confusing questions. The original survey in English was translated into Arabic and then back-translated into English to rule out differences that could compromise the intended meaning.

\section{ANALYSIS AND RESULTS}

\section{Characteristics of the Sample}

Of the 600 questionnaires distributed, 446 questionnaires were completed, 400 of which were judged as appropriate, leading to a response rate of $89.68 \%$. The final sample consisted of 164 males and 236 females $(41 \%$ and $59 \%$ of the sample, respectively). The demographic analysis (Table 1) showed the highest concentration of participants being in the 18 to 25 years old age category $(66.8 \%)$. The age distribution reflects the higher percentage of undergraduates in universities with the bulk of participants $(77.3 \%)$ pursuing an undergraduate degree.

Table 1 also summarizes the results of the demographic distribution for both the Levant and Gulf regions. In the Levant region, the percentages of female and male respondents were respectively $52.5 \%$ and $47.5 \%$, compared to $65.5 \%$ females and $34.5 \%$ males in the Gulf region. The latter percentage distribution seems to represent the difference in gender ratios amongst university students in the Gulf area (Paschyn, 2013). The age distribution among both regions was similar.

The level of education distribution between the two regions showed different results. The percentage of respondents pursuing an undergraduate degree varied significantly between the Levant $(67.5 \%)$ and the Gulf $(87 \%)$ regions. The percentage of people attending a master's degree program was higher in the Levant $(27.5 \%)$ than 
in the Gulf (11.5\%) region. There were also large variations in terms of participants holding a doctoral degree between the Levant (3\%) and the Gulf $(0.5 \%)$ region.

Although insightful in terms of the samples characteristics, demographics are supposed to implicitly affect respondents' beliefs, values, and hence consumption orientations.

Table 1 Demographics by regional distribution: the Gulf vs. Levant

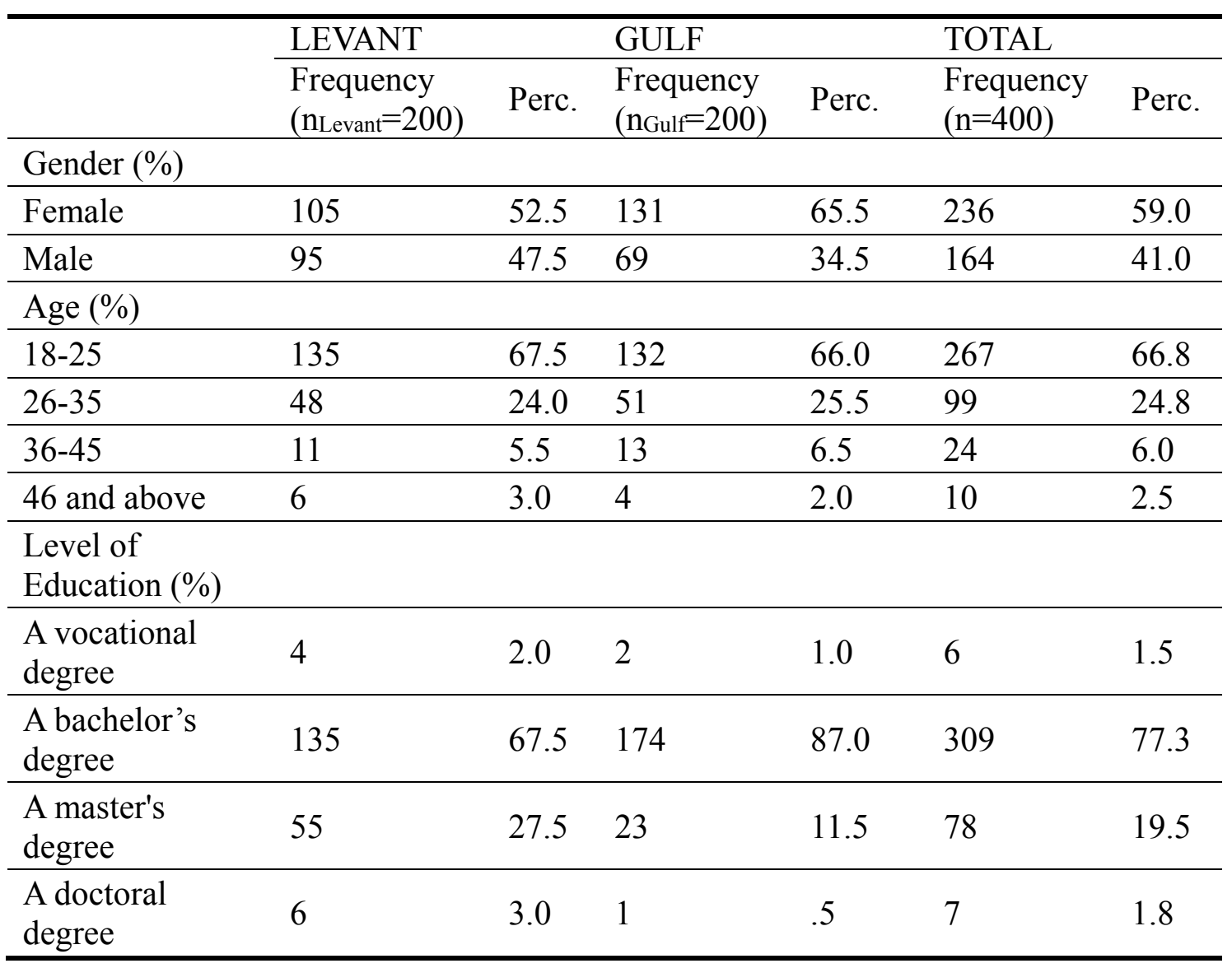

\section{Assessment of Measures}

This research uses a confirmatory factor analysis (CFA) employing LISREL because it is testing an existent theory. Table 2 reveals the results obtained from the CFA and provides support for the scale's reliability for both regions. The results confirm that all the items retained in the survey load substantively on their related factors with no significant cross-loadings identified for either region. Table 3 demonstrates the model fit and proves that the seven-factor paradigm was adequate in both the total sample and each region separately. The model fit was specifically evaluated by calculating (a) the root mean square error of approximation (RMSEA), where values less than 0.06 indicate a good fit (Hu \& Bentler, 1995); (b) the Tucker- 
Lewis index (TLI), also known as the Non-Normed Fit Index (NNFI); and (c) the comparative fit index (CFI) as well as the Goodness of Fit Index (GFI), where any value above 0.90 indicates a reasonable fit (Hair, Anderson, Tatham, \& Black, 1998). Moreover, the value of the Adjusted Goodness of Fit Index (AGFI) should be more than 0.80 and the results of the Root Mean Square Residual (RMR) less than 0.05 (Gefen, Straub \& Boudrea, 2000). The chi-squared was also computed. Table 4 exhibits the correlation matrices for both the total sample and each region alone. Lastly, Table 5 presents the SEM model results for the total sample as well as the Levant and Gulf regions to test the hypotheses proposed.

Both a standardized factor loading and an average variance extracted (AVE) were computed to validate this model for each regional market (Table 2). In factor loading, each sub-item should load higher than 0.6 on its own construct, yet remarkably lower on the other constructs. A value of 0.6 and above is generally considered excellent, values between 0.5 and 0.6 are moderate, and any value below 0.5 is questionable (Hair, Anderson, Tatham, \& Black, 1992). As for the AVE, also known as convergent validity, values should be equal to or above 0.5 (Hair et al., 1992).

Table 2 demonstrates that the standardized factor loading for each sub-item of all the seven constructs loaded above the preferred value of 0.6 for both regions (except for sub-item CONS4 in the Gulf region). The AVE results for both markets were consistently above the moderate acceptable cut off value of 0.5 .

Both Cronbach's alpha and composite reliability were calculated to measure the overall reliability and independence of the scale for each regional market. The higher the Cronbach's alpha and composite reliability, the more reliable the model is and the more independent the latent variables of the scale are. The Cronbach's alpha and composite reliability for the constructs of quality, hedonism, conspicuousness, exclusivity, extended-self, face-saving, and group orientation proved to be reliable across both markets. Indeed, all alpha values were above the standard value of 0.7 , proving the reliability and independence of the items. It is important to highlight that the researchers dropped some items from each of the constructs of quality (QUA3: their brand names, QUA4: their country of origin), extended-self (EXTS1: people buy luxury goods to reveal a little of who they are), and group orientation (GO4: If there is a conflict between my interest and my family's interest, I'll put the priority on mine) to increase reliability and AVE results. Specifically, alpha if item is deleted was calculated to indicate the change in the Cronbach's alpha that would occur if the items with the lowest standardized factor loading were deleted. If an item did cause a 
substantial decrease in alpha, then that item was dropped from the questionnaire to improve reliability.

Table 2 Confirmatory Factor Analysis: Total versus by regions (Levant vs. Gulf)

\begin{tabular}{|c|c|c|c|c|c|}
\hline Construct & Item & $\begin{array}{l}\text { Standardised } \\
\text { Factor } \\
\text { Loading } \\
\text { (Levant, } \\
\text { Gulf) } \\
\end{array}$ & $\begin{array}{l}\text { Cronbach's } \alpha \\
\text { (Levant, } \\
\text { Gulf) }\end{array}$ & $\begin{array}{l}\text { Composite } \\
\text { Reliability } \\
\text { (Levant, } \\
\text { Gulf) }\end{array}$ & $\begin{array}{l}\text { AVE } \\
\text { (Levant, } \\
\text { Gulf) }\end{array}$ \\
\hline \multirow{4}{*}{$\begin{array}{l}\text { Quality } \\
\text { (QUA) }\end{array}$} & QUA1 & $0.85 / 0.77$ & \multirow{4}{*}{$0.76 / 0.72$} & \multirow{4}{*}{$0.86 / 0.83$} & \multirow{4}{*}{$0.61 / 0.55$} \\
\hline & QUA2 & $0.83 / 0.76$ & & & \\
\hline & QUA5 & $0.68 / 0.74$ & & & \\
\hline & QUA6 & $0.74 / 0.68$ & & & \\
\hline \multirow{5}{*}{$\begin{array}{l}\text { Hedonism } \\
\text { (HED) }\end{array}$} & HED1 & $0.82 / 0.85$ & \multirow{5}{*}{$0.83 / 0.84$} & \multirow{5}{*}{$0.87 / 0.89$} & \multirow{5}{*}{$0.57 / 0.62$} \\
\hline & HED2 & $0.76 / 0.76$ & & & \\
\hline & HED3 & $0.71 / 0.80$ & & & \\
\hline & HED4 & $0.70 / 0.83$ & & & \\
\hline & HED5 & $0.78 / 0.68$ & & & \\
\hline \multirow{6}{*}{$\begin{array}{l}\text { Conspicuousness } \\
(\mathrm{CON})\end{array}$} & CONS1 & $0.67 / 0.75$ & \multirow{6}{*}{$0.83 / 0.81$} & \multirow{6}{*}{$0.87 / 0.86$} & \multirow{6}{*}{$0.54 / 0.52$} \\
\hline & CONS2 & $0.76 / 0.70$ & & & \\
\hline & CONS3 & $0.79 / 0.71$ & & & \\
\hline & CONS4 & $0.61 / 0.45$ & & & \\
\hline & CONS5 & $0.78 / 0.81$ & & & \\
\hline & CONS6 & $0.78 / 0.84$ & & & \\
\hline \multirow{4}{*}{$\begin{array}{l}\text { Exclusivity } \\
(\text { EXC) }\end{array}$} & $\mathrm{EXC1}$ & $0.75 / 0.90$ & \multirow{4}{*}{$0.77 / 0.82$} & \multirow{4}{*}{$0.84 / 0.88$} & \multirow{4}{*}{$0.58 / 0.65$} \\
\hline & EXC2 & $0.90 / 0.89$ & & & \\
\hline & EXC3 & $0.60 / 0.72$ & & & \\
\hline & EXC4 & $0.76 / 0.71$ & & & \\
\hline \multirow{4}{*}{$\begin{array}{l}\text { Extended Self } \\
\text { (EXTS) }\end{array}$} & EXTS2 & $0.83 / 0.84$ & \multirow{4}{*}{$0.73 / 0.87$} & \multirow{4}{*}{$0.84 / 0.92$} & \multirow{4}{*}{$0.58 / 0.73$} \\
\hline & EXTS3 & $0.58 / 0.83$ & & & \\
\hline & EXTS4 & $0.82 / 0.88$ & & & \\
\hline & EXTS5 & $0.79 / 0.87$ & & & \\
\hline \multirow{4}{*}{$\begin{array}{l}\text { Face Saving } \\
(\mathrm{FS})\end{array}$} & FS1 & $0.80 / 0.86$ & \multirow{4}{*}{$0.78 / 0.88$} & \multirow{4}{*}{$0.86 / 0.91$} & \multirow{4}{*}{$0.61 / 0.73$} \\
\hline & FS2 & $0.60 / 0.85$ & & & \\
\hline & FS3 & $0.82 / 0.82$ & & & \\
\hline & FS4 & $0.87 / 0.89$ & & & \\
\hline \multirow{3}{*}{$\begin{array}{l}\text { Group } \\
\text { Orientation (GO) }\end{array}$} & GO1 & $0.70 / 0.68$ & \multirow{3}{*}{$0.62 / 0.625$} & \multirow{3}{*}{$0.80 / 0.75$} & \multirow{3}{*}{$0.57 / 0.51$} \\
\hline & $\mathrm{GO} 2$ & $0.83 / 0.805$ & & & \\
\hline & GO3 & $0.74 / 0.65$ & & & \\
\hline
\end{tabular}

Note: All factor loadings significant as a minimum $p<0.01$. Correlations among all item measurement errors are restricted to 0 . All latent factors are allowed to co-vary freely. 


\section{Testing the Model Fit}

Table 3 shows that the RMSEA for the total sample was 0.033 , indicating a good fit in that aspect. Both the Levant (0.043) and Gulf (0.049) regions also had reasonable results that fit the criteria. Each of the CFI, TLI, and NFI results for both the total sample $(0.96,0.96$, and 0.92 , respectively) and each region alone-Levant (0.91, 0.92, and 0.905, correspondingly) and Gulf (0.96, 0.96, and 0.91, respectively) - exceeded the required value of 0.90 . The GFI marginally accepted values that were above 0.80 (Gefen et al., 2000) for the total sample (0.81), Levant (0.86), and Gulf (0.81). As for the AGFI, the results for the total sample, Levant, and Gulf regions $(0.80,0.82$, and 0.805 , respectively) were all adequate as, according to Gefen et al. (2000), any value above 0.80 is considered acceptable. The chi-squared results were 562.87 for the total sample, 536.45 for Levant, and 578.87 for Gulf. The normed chi squared (NC), computed as chi squared divided by degrees of freedom, was consistently below 2 (Ullman, 2001) and, hence, was considered acceptable. The RMR should have a value less than 0.05 (Hair et al., 1998); the RMR for the total sample was 0.04, for Levant was 0.047, and for Gulf was 0.032. Steiger (1990) encouraged the use of confidence intervals to evaluate the accuracy of RMSEA estimates in which LISREL 8 reports a 90\% interval around the RMSEA value (Byrne, 1998). In fact, when RMSEA is small yet has a wide confidence interval, it is concluded that the estimated discrepancy value is quite imprecise, thereby negating any possibility to determine the degree of fit in the population accurately. On the other hand, a very narrow confidence interval would argue for good precision of the RMSEA value in reflecting model fit in the population (Byrne, 1998). The results for the $90 \%$ confidence interval for RMSEA for the total sample, Levant, and Gulf were [0.018;0.044], [0.072;0.081], and [0.057; 0.071], respectively. Moreover, LISREL 8 allows us to test for the closeness of fit by testing the hypothesis that the error of approximation has an associated probability of less than 0.05 (Byrne, 1998). Joreskog and Sorbom (1996a) have suggested that the p-value for this test should be greater than 0.05 ; indeed the $p$-value for the test of close fit for the total sample was 0.2 , for Levant was 0.17 , and for Gulf was 0.1 . Thus, RMSEA was proved to be less than 0.05 .

\section{Correlation Analysis}

Table 4 describes the correlation metrics of Confucian values with the factors of luxury perception for the total sample as well as each market region individually. There is no to a weak correlation if coefficients range between \pm 0.00 and 0.29 , a moderate correlation if between \pm 0.30 and 0.69 , and a strong correlation if coefficients vary between \pm 0.70 and 1 (Jackson, 2013). The Confucian values of 
group orientation and face-saving both have a relatively significant correlation with all constructs related to luxury perception as well as with each other in the total sample. For the total sample, the correlation (0.91) between group orientation and face-saving is statistically significant. Group orientation shows moderate statistically significant correlations with quality (0.46), extended-self (0.55), exclusivity (0.57), conspicuousness (0.51), and hedonism (0.40). Face-saving also exhibits moderate correlations with each of the constructs pertaining to quality (0.36), extended-self (0.42), exclusivity (0.42), and conspicuousness (0.33) as well as an insignificant correlation with hedonism (0.29). A moderate correlation exists between the construct of quality and extended-self (0.47), exclusivity (0.52), conspicuousness (0.55), and hedonism (0.46). The correlation of extended-self with every other construct also proves to be moderate with exclusivity $(0.63)$, conspicuousness $(0.68)$, and hedonism (0.57). The construct of exclusivity had a strong correlation with conspicuousness (0.73) and a moderate one with hedonism (0.63). Finally, conspicuousness has a moderate correlation with hedonism (0.69). Comparing the correlations of both market regions to one another, minor discrepancies were found, with most factors yielding moderate to strong statistical correlations with one another, except for two in the Levant region.

Table 3 Model Fit Testing for Total Versus Regional Markets

\begin{tabular}{llll}
\hline & $\begin{array}{l}\text { Total } \\
\text { Sample }\end{array}$ & Levant & Gulf \\
\hline Sample Size & 400 & 200 & 200 \\
\hline Minimum Fit Function Chi-Square & 562.87 & 536.45 & 578.87 \\
\hline Degrees of Freedom & 394 & 394 & 394 \\
\hline $\begin{array}{l}\text { Root Mean Square Error of Approximation } \\
\text { RMSEA) }\end{array}$ & 0.033 & 0.043 & 0.049 \\
\hline 90 Percent Confidence Interval for RMSEA & $0.018 ;$ & $0.072 ;$ & $0.057 ;$ \\
\hline $\begin{array}{l}\text { P-Value for Test of Close Fit (proving that RMSEA } \\
<0.05)\end{array}$ & 0.044 & 0.081 & 0.071 \\
\hline Normed Fit Index (NFI) & 0.92 & 0.17 & 0.1 \\
\hline $\begin{array}{l}\text { Non-Normed Fit Index (NNFI) - Tucker Lewis } \\
\text { nndex (TLI) }\end{array}$ & 0.96 & 0.92 & 0.96 \\
\hline Comparative Fit Index (CFI) & 0.96 & 0.91 & 0.96 \\
\hline Root Mean Square Residual (RMR) & 0.04 & 0.047 & 0.032 \\
\hline Goodness of Fit Index (GFI) & 0.81 & 0.86 & 0.81 \\
\hline Adjusted Goodness of Fit Index (AGFI) & 0.80 & 0.82 & 0.805 \\
\hline
\end{tabular}

Notes: Correlations among all item measurement errors are restricted to 0. All latent factors are allowed to co-vary freely; $p>0.05$ 


\section{Hypothesis Testing}

The hypotheses were tested utilizing structural equation modeling (SEM) to facilitate the estimation of a series of interdependent, multiple regression equations simultaneously by specifying the structural model used by the statistical program (Hair, Black, Babin, Anderson, \& Tatham, 2006). The covariance matrix was used to empirically assess the strength of each relationship (Hair et al., 2006). The results of the SEM models are given in Table 5. H1, establishing the link between quality and face-saving in Arab countries, is supported $(\mathrm{r}=-2.63$, $\mathrm{t}$-value $=-1.96, \mathrm{p}=0.025)$ implying that if an item is of a higher quality, then the concept of face-saving is viewed more positively. $\mathrm{H} 2$ tests the link between quality and group orientation $(\mathrm{r}=$ 3.04 , t-value $=2.21, \mathrm{p}=0.014$ ), proving that consumers who place high importance on group orientation view quality as an important factor when purchasing a luxury. H3 and $\mathrm{H} 4$ test the negative relationship between hedonism and face-saving as well as hedonism and group orientation, respectively, among Arab consumers; both H3 ( $\mathrm{r}=$ 2.87, $\mathrm{t}$-value $=-1.3, \mathrm{p}=0.097)$ and $\mathrm{H} 4(\mathrm{r}=-2.2$, $\mathrm{t}$-value $=-1.21, \mathrm{p}=0.113)$ are insignificant. Accordingly, it is concluded that hedonism has no apparent negative effects on either face-saving or group orientation. H5, testing the positive influence of conspicuousness on face-saving, proved to be significant $(\mathrm{r}=4.66$, $\mathrm{t}$-value $=1.8654, \mathrm{p}$ $=0.031$ ), implying that consumers who place a high importance on maintaining their face tend to consume conspicuously. H6, which studies the link between conspicuousness and group orientation, proved to be insignificant $(\mathrm{r}=4.87$, $\mathrm{t}$-value $=$ $1.45, \mathrm{p}=0.074)$, entailing that conspicuousness is not positively viewed by those emphasizing group orientation. Both $\mathrm{H} 7(\mathrm{r}=3.83$, $\mathrm{t}$-value $=2.45, \mathrm{p}=0.007)$ and $\mathrm{H} 8(\mathrm{r}$ $=4.31, \mathrm{t}$-value $=4.1547, \mathrm{p}=0.0$ ) establish the relationship between exclusivity and face-saving as well as exclusivity and group orientation, respectively, meaning that Arab consumers who value the aspects of face-saving and group orientation positively view the construct of exclusivity. Lastly, $\mathrm{H} 8(\mathrm{r}=3.28$, $\mathrm{t}$-value $=2.6478, \mathrm{p}=0.004)$ and H9 ( $\mathrm{r}=3.75, \mathrm{t}$-value $=3.415, \mathrm{p}=0.0)$ study the connection between extended self and face-saving and group orientation in that order, thereby showing that Arabs who place importance on face-saving and group orientation positively associate with the extended-self construct.

\section{DISCUSSION}

\section{The Arab World Consumer}

Arab people are known to depend more on the group than on their individuality (Kabaskal \& Bodur 2002); thus, some of the results were of no surprise whereas others were relatively unforeseen. Acknowledging the mindset of the Arab consumers 
and how they place high importance on ensuring group harmony and maintaining a positive social image, the results obtained in this study have both significant academic and managerial implications for luxury brand marketers operating in the Arab world. The hypotheses proposed in this study shed light on the different and changing social makeup within the various Arab countries. The cultural dimensions of face-saving and group orientation appear to influence the significance of several factors pertaining to luxury - namely, quality, hedonism, conspicuousness, exclusivity, and extended-self. This study validated some previously established Arab countries' characteristics proposed by Hofstede's work (1991) while challenging some other attributes, like collectivism, in countries like Qatar and Jordan (Aldulaimi \& Zedan, 2012).

Table 4 Correlation Matrices

\begin{tabular}{|c|c|c|c|c|c|c|c|}
\hline & \multicolumn{2}{|c|}{$\begin{array}{l}\text { CONFUCIAN } \\
\text { VALUES }\end{array}$} & \multicolumn{3}{|c|}{ LUXURY PERCEPTION } & \multirow[b]{2}{*}{ CONS } & \multirow[b]{2}{*}{ HED } \\
\hline & $\mathrm{GO}$ & FS & QUAL & $\begin{array}{l}\text { EXT } \\
\text { S }\end{array}$ & $\mathrm{EXC}$ & & \\
\hline \multicolumn{8}{|c|}{ AGGREGATE SAMPLE $(\mathrm{n}=400)$} \\
\hline GO & 1 & & & & & & \\
\hline FS & .91 & 1 & & & & & \\
\hline QUAL & .46 & .36 & 1 & & & & \\
\hline EXTS & .55 & .42 & .47 & 1 & & & \\
\hline EXC & .57 & .42 & .52 & .63 & 1 & & \\
\hline CONS & .51 & .33 & .55 & .68 & .76 & 1 & \\
\hline HED & .40 & .29 & .46 & .57 & .63 & .69 & 1 \\
\hline \multicolumn{3}{|c|}{$\begin{array}{l}\text { LEVANT vs. GULF REGIONS } \\
\text { (nGULF }=200 \text {, above diagonal) }\end{array}$} & Levant & EVANT $=2$ & , belo & diagona & )$/ \mathrm{Gl}$ \\
\hline GO & 1 & .97 & .39 & .35 & .52 & .36 & .43 \\
\hline FS & .85 & 1 & .41 & .32 & .53 & .4 & .47 \\
\hline QUAL & .53 & .31 & 1 & .47 & .59 & .59 & .62 \\
\hline EXTS & .75 & .52 & .47 & 1 & .69 & .73 & .77 \\
\hline EXC & .62 & .31 & 345 & .57 & 1 & .87 & .87 \\
\hline CONS & .66 & .26 & .51 & .63 & .65 & 1 & .92 \\
\hline HED & .37 & .11 & .3 & .37 & .39 & .46 & 1 \\
\hline
\end{tabular}

All correlations were significant at the 0.05 level (2-tailed) except for the correlation between hedonism and face saving, conspicuousness and face saving in the Levant, and hedonism and face saving in the total sample.

The results implied that Arab consumers who value both face-saving and group orientation particularly emphasize the aspect of quality. When purchasing an item, Arab consumers appear to emphasize the quality of work put into this product, which in turn allows others to perceive this product as luxurious. Consumers who can afford 
the price of quality products are typically viewed more favorably by others within their group, which helps them maintain their face and join the group they aspire to (Roux, 1995).

Table 5 Results of the SEM Model

\begin{tabular}{lllll}
\hline \multirow{2}{*}{ HYP } & Relationship & $\begin{array}{l}\text { Standardized } \\
\text { coefficient, } \\
\text { (TS, LEV, GF) }\end{array}$ & $\begin{array}{l}\text { t-value } \\
\text { (TS, LEV, GF) }\end{array}$ & $\begin{array}{l}\text { p-value } \\
\text { (TS, LEV, GF) }\end{array}$ \\
\hline 1 & QUA \& FS & $-2.63 /-0.053 /-1.94$ & $-1.96 /-1.73 /-1.41$ & $0.025 * / 0.042 * / 0.079$ \\
\hline 2 & QUA \& GO & $3.04 / 0.99 / 2.36$ & $2.21 / 3.52 / 1.74$ & $0.014 * / 0.0 * / 0.041^{*}$ \\
\hline 3 & HED \& FS & $-2.87 /-0.87 /-2.87$ & $-1.3 /-1.72 /-1.54$ & $0.097 / 0.043 * / 0.062$ \\
\hline 4 & HED \& GO & $-2.2 / 0.96 / 2.89$ & $-1.21 / 1.86 / 1.58$ & $0.113 / 0.031 * / 0.057$ \\
\hline 5 & CONS \& FS & $4.66 /-1.09 /-3.5$ & $1.8654 /-2.35 /-1.56$ & $0.031 * / 0.009^{*} / 0.059$ \\
\hline 6 & CONS \& GO & $4.87 / 1.58 / 3.92$ & $1.45 / 3.72 / 1.78$ & $0.074 / 0.0 * / 0.038^{*}$ \\
\hline 7 & EXC \& FS & $3.83 /-0.82 /-2.84$ & $2.45 /-2.09 /-1.48$ & $0.007 * / 0.018^{*} / 0.069$ \\
\hline 8 & EXC \& GO & $4.31 / 1.32 / 3.34$ & $4.1547 / 3.61 / 1.78$ & $0.0 * / 0.0 * / 0.038^{*}$ \\
\hline 9 & EXTS \& FS & $3.28 /-0.46 /-2.42$ & $2.6478 /-1.37 /-1.45$ & $0.004 * / 0.085 / 0.074$ \\
\hline 10 & EXTS \& GO & $3.75 / 1.15 / 2.91$ & $3.415 / 3.74 / 1.78$ & $0.0 * / 0.0 * / 0.038^{*}$ \\
\hline
\end{tabular}

Note: *Significant at the 0.05 Level

(TS: Total Sample, LEV: Levant, GF: Gulf)

On the other hand, although hedonism is not an important factor impacting luxury products' purchase decision in most Arab countries, this idea is changing rapidly. Although the extant literature proposes that hedonism is negatively perceived in light of face-saving and group orientation (Monkhouse, Barnes, \& Stephan, 2011), the opposite is perfectly explainable in the context of Arab markets. Indeed, hedonism can have a somewhat positive impact on both face-saving and group orientation. Individuals need to feel confident and satisfied when making a luxury purchase (Berry, 1994). As such, the pleasure from obtaining a product can be projected onto the group and, hence, can positively influence this group to reinforce future purchases of the same brand while implicitly saving the initial purchaser's face (Marciniack \& Mohsen, 2014).

Conspicuousness gives the consumer the opportunity to belong to a certain group as a result of the apparent social status inferred from such consumption (O'Cass \& Frost, 2002). The way Arab societies are structured, whereby an individual's social position is bestowed upon him/her from birth (Teimourpour \& Hanzaee, 2011), conspicuousness allows that person to portray belongingness to a particular social group in a tangible manner through possessions. However, because research results 
propose that a majority of Arab citizens value group orientation (Kabaskal \& Bodur, 2002), flaunting conspicuousness may not always be appreciated as it may cause group disharmony. In fact, Islam is the dominant religion in the Arab region, and its teachings emphasize the importance of leading a simple life with little emphasis on worldly possessions. Lord and Putrevu (2005) propose that religion is associated with some motivations leading to more specific consumption activities; this explains why conspicuousness may not be viewed favorably by certain religious groups.

Social groups in Arab societies are exclusive to its members (Dirani, 2008); as such, individuals who seek to save face and remain in their particular group will naturally value the dimension of exclusivity. Accordingly, the feeling they experience when purchasing a luxury product that is readily available to only a small portion of the population will make them feel closer to individuals within their elite group. In Arab societies, an individual often belongs to several groups at the same time. As such, exclusivity may have its drawbacks on the choices an individual makes whereby all the groups to which he/she belongs should be taken into consideration in order to maintain harmony amongst them (Marciniak \& Mohsen, 2014).

Finally, as individuals in Arab societies are known to care for the benefit of the group on a large scale, it is no surprise that individuals regard highly both group orientation and face-saving when considering the extended-self component as one's belongings, similar to those possessed by others in one's surroundings, are perceived as a means to emphasize group harmony, unity, and one's public image.

\section{Comparison between the Levant and Gulf Consumers}

For a long time, foreign firms have viewed the Arab consumers as a homogeneous group rather than as several heterogeneous sub-markets (Al-Khatib, Vitell, Rexeisen, \& Rawwas, 2005). Although one might assume that there are no major differences between the Levant and Gulf regions, this assumption is challenged by the findings of this study, with consumers in the Levant region putting relatively more importance on both face-saving and group orientation. Indeed, countries in both regions have been witnessing changes in the make-up of their societies, thereby affecting both their culture and their social norms (Al-Khatib et al., 2005).

It is no secret that the social make-up of the Gulf region by and large comprises expatriates who have helped build these countries' economies and infrastructure (Attiyah, 1996). This reality seems to explain why family bonds and social norms are becoming less important, with a dominant shift toward individualism. Concretely, a qualitative study of consumers in the Gulf region, released in 2002 by the NFO World Group, suggests that the Gulf is witnessing dramatic changes in culture and consumer 
attitudes. The study indicates a rise in individualism and the growth of nuclear families in a region that has traditionally thrived on collectivity and an extended family structure (Al-Khatib et al., 2005). Face-saving and group orientation both play a significant role when consumers from the Levant region are choosing a luxury product in comparison to consumers from the Gulf region. A high quality item is viewed more favorably by consumers in the Levant region, as these still take into consideration the group to which they belong or wish to be affiliated with (Dirani, 2008). Face-saving is also viewed more favorably in the Levant than in the Gulf region due to the different social make-up of both regions; as such, quality is less important to Gulf consumers as these increasingly individualistic consumers will care less about the product quality perception of surrounding people (Neal, Finlay, Catana, \& Catana, 2007).

Conspicuousness is clearly more important to individuals in the Levant region than those in the Gulf region. Numerous researchers have discussed the belief that "individuals may consume luxury products to "define themselves to themselves" (Tsai, 2005; Wiedmann et al., 2009). In this perspective, consumers of the Gulf region seem to buy products according to their own liking, with no concern for face-saving and little attention to group orientation, whereas people in the Levant region appear to be more concerned with satisfying the group and maintaining face (Marciniak \& Mohsen, 2014).

Hedonism plays a major role for consumers in the Gulf region as those seeking self-pleasure more readily than those in the Levant region (Al-Khatib et al., 2005), thereby appreciating the feeling of exclusivity more. However, in the Levant region, both hedonism and exclusivity are viewed unfavorably as they are believed to disrupt group harmony (Neal et al., 2007).

Moreover, although the Gulf appears to be shifting toward individualism (NFO Merac, 2001), it should be recognized that these changes are partially the result of the large number of expatriates; however, the nationals still firmly hold to the group, focusing on harmony among individuals in their close-knit community. Nevertheless, expatriates could influence some Gulf nationals who would be content doing what they see fit for their own good.

As individuals in both regions are known to look after one another and care for face-saving, the perceptions of the extended-self regarding one's belongings are perceived as a means to either emphasize group harmony, unity, and one's public image or refute these factors. By all means, this aspect of luxury perception appears to be similar in both regions. 


\section{MANAGERIAL IMPLICATIONS, LIMITATIONS, AND FUTURE RESEARCH}

The findings of this study support the belief that characteristics like inclinations toward interpersonal impact and concern about others' opinions are motivators of status consumption irrespective of financial capabilities or social status. The study results demonstrate that Arab consumers appear to be willing to pay for prominent products that imply rank. This finding is an invitation to marketers, advertisers, and retailers to target this attractive consumer segment. These parties can benefit from the psychographic dimensions examined to categorize status seekers. Individuals who seek status typically evaluate themselves according to how their reference group views them. Accordingly, marketing managers who are able to correctly identify trendsetters in groups or societies can capitalize on influencing followers who value what others in their reference group believe. Moreover, as Arab countries are known to enjoy a relatively young population, marketers would benefit from shifting their focus to younger adults as the latter are the consumers who depend most heavily on social referencing to make an agreeable buying decision (Aldulaimi \& Zedan, 2012). When identifying the importance that Arabs place on group opinion, harmony, and acceptance, it appears crucial to Western luxury brand managers to properly position their offerings to the "Arab consumer." In contrast with the near past, whereby marketers needed to promote the "sense of group belonging and conformity" and to stress the use of luxury goods in terms of social status reflection, today's marketers must recognize the perceptible shift in social values toward increased individualism across the Arab world (Aldulaimi \& Zedan, 2012). Furthermore, marketers need to adjust the advertisement campaigns of luxury brands to emphasize the spreading perception of hedonistic value. In light of this finding, marketing strategists need to recognize that the Arab region is not as homogeneous as was once believed. Accordingly, market penetration strategies should clearly reflect the marketers' ability to distinguish among the various market values and most desired luxury products.

Regardless of what this research has to offer, its limitations are recognized. First and foremost, the research is restricted to only certain aspects of personal values and cultural factors influencing one's luxury product purchase intention. Future studies could tackle additional factors affecting conspicuous consumption and look into the intricacies of different Arab societies' characteristics. Second, the sample size of this study, although sufficient to get an overall feel of the university population, is not big enough to generate generalizable findings to other Arab countries. Studying only four countries undoubtedly has its limitations; as such, carrying a cross-cultural study across all Arab countries could be insightful to luxury brand retailers. Lastly, after 
acknowledging that convenience sampling undeniably restricts the capacity of the research to fairly represent the target population, the broadening of the results beyond this specific sample would be inappropriate. Although this method is deemed useful for investigative research, additional research can be carried out with a more diverse consumer probability sample.

\section{REFERENCES}

Acikalin, S., Gul, E., \& Develioglu, K. (2009). Conspicuous consumption patterns of Turkish youth: Case of cellular phones. Young Consumers: Insights and Ideas for Responsible Marketers, $10(3)$,

199-209. http://dx.doi.org/10.1108/17473610910986017

Abosag, I. \& Farah M. F. (2014). The influence of religiously motivated consumer boycotts on brand image, loyalty and product judgment. European Journal of Marketing, 48(11/12): 2262-2283. http://dx.doi.org/10.1108/EJM-12-2013-0737

Aldulaimi, S. H., \& Zedan, A. (2012). Leadership's individualism culture effect on affective commitment to organizational change in Qatar. Journal of Modern Marketing Research, 1, 1-9.

Alkailani, M., Azzam, I., \& Athamneh, A. B. (2012). Replicating Hofstede in Jordan: ungeneralized, reevaluating the Jordanian culture. International Business Research, 5(4), 71-80. http://dx.doi.org/10.5539/ibr.v5n4p71

Al-Khatib, J. A., Vitell, S. J., Rexeisen, R., \& Rawwas, M. (2005). Inter-country differences of consumer ethics in Arab countries. International Business Review, 14(4), 495-516. http://dx.doi.org/10.1016/j.ibusrev.2005.04.001

Asia Market Intelligence. (2003). Retrieved October 8, 2013, from www.amigroup.com

Atiyyah, H. S. (1996). Expatriate acculturation in Arab Gulf countries. Journal of Management Development, 15(5), 37-47. http://dx.doi.org/10.1108/02621719610117231

At-Twaijri, M. I., \& Al-Muhaiza, I. A. (1996). Hofstede's cultural dimensions in the GCC countries: An empirical investigation. International Journal of Value Based Management, 9(2), 121-131. http://dx.doi.org/10.1007/BF00440149

Bagwell, L. S., \& Bemheim, D. B. (1996). Veblen effects in a theory of conspicuous consumption. American Economic Review, 86(3), 349-373.

Barakat, H. (1993). The Arab World: society, culture, and state. Berkeley: University of California Press.

Belk, R. W. (1988). Possessions and the extended self. Journal of Consumer Research, 15(2), 139-168. http://dx.doi.org/10.1086/209154 
Berthon, P., Pitt, L. F., \& Campbell, C. (2009). Does brand meaning exist in similarity or singularity? Journal of Business Research, 62(3), 356-361. http://dx.doi.org/10.1016/j.jbusres.2008.05.015

Berry, C. (1994). The idea of luxury. a conceptual and historical investigation. Camrbidge: Cambridge University Press.

Bond, M. H. (1991). Beyond the chinese face: insights from psychology. Oxford: Oxford University Press.

Byrne, B. M. (1998). Structural Equation Modeling With Lisrel, Prelis, and Simplis: Basic Concepts, Applications, and Programming. Mahwah, NJ: Lawrence Erlbaum Associates, Inc.

Central Intelligence Agency. (2014). Lebanon, Jordan, Oman and Qatar. In The World Factbook. Retrieved from: https://www.cia.gov/library/publications/theworld-factbook/geos/mu.html

Chaudhuri, H. R., \& Majumdar, S. (2006). Of diamonds and desires: understanding conspicuous consumption from a contemporary marketing perspective. Academy of Marketing Science Review, 2006 (11). Available: http://www.amsreview.org/articles/chaudhuri08-2005.pdf

Dirani, K. M. (2008). Individualism and collectivism in Lebanon: correlations with socioeconomic factors and effects on management and human resources practices. Advances in International Management, 21, 211-233. http://dx.doi.org/10.1016/S1571-5027(08)00009-0

Dittmar, H. (1994). Material possesions as stereotypes: material images of different socio-economic groups. Journal of Economic Psychology, 15(4), 561-585.

Dubois, B., \& Duquesne, P. (1993). The market for luxury goods: income versus culture. European Journal of Marketing, 27(1), 35-45. http://dx.doi.org/10.1108/03090569310024530

Engel, J. F., Blackwell, R. D., \& Miniard, P. W. (1990). Consumer behavior (6 ${ }^{\text {th }}$ ed.). Chicago: Chicago Dryden Press.

Farah, M. F., \& Newman A. J. (2010). Exploring consumer boycott intelligence using a socio-cognitive approach. Journal of Business Research, 63(4), 347-355. http://dx.doi.org/10.1016/j.jbusres.2009.03.019

Farley, J. U., \& Lehmann, D. R. (1994). Cross national laws and differences in market response. Management Science, 40(1), 111-122. http://dx.doi.org/10.1287/mnsc.40.1.111

Gefen, D., Straub, D., \& Boudreau, M. C. (2000). Structural equation modeling and regression: Guidelines for research practice. Communications of the association for information systems, 4(1), 7. 
Gentry, J. W., Putrevu, S., Shultz, I. I., \& Commuri, E. S. (2001). How now Ralph Lauren? the separation of brand and product in a counterfeit culture. Advances in Consumer Research, 28(1), 258-265.

Gunter, B. \& Furnham, A. (1998). Children as consumers: a psychological analysis of the young people's market: international series in social psychology. Routledge: London. http://dx.doi.org/10.4324/9780203272947

Hair, J. F., Anderson, R. E., Tatham, R. L., \& Black, W. C. (1992). Multivariate data analysis with readings. New York: Macmillan.

Hair, J. F., Anderson, R. E., Tatham, R. L., \& Black, W. C. (1998). Multivariate data analysis (Fifth Edition). New Jersey: Prentice-Hall Inc..

Hair, J. F., Black, W. C., Babin, B. J., Anderson, R. E., \& Tatham, R. L. (2006). Multivariate data analysis (Vol. 6). Upper Saddle River, NJ: Pearson Prentice Hall.

Hofstede, G. (1983). The cultural relativity of organizational practices and theories. Journal of International Business Studies, 14(2) , 75-89.

Hogg, M. A. \& Vaughan, G. M. (2002). Social psychology ( $3^{\text {rd }}$ ed.). London: Prentice Hall.

Hosfstede, G. (1980). Culture's consequences: international differences in workrelated values. Newbury Park, CA.: Sage Publications.

Hofstede, G. (1991). Cultures and organizations: software of the mind. Maidenhead: McGraw-Hill.

Hu, L. T., \& Bentler, P. M. (1995). Evaluating model fit. In R. H. Hoyle (Ed.), Structural equation modeling: Concepts, issues, and applications (pp. 76-99). Thousand Oaks, CA: Sage

Hui, H., \& Triandis, H. (1986). Individualism-collectivism: A study of cross-cultural researchers. Journal of Cross Cultural Psychology, 17(2), 225-248. http://dx.doi.org/10.1177/0022002186017002006

Husic, M., \& Cicic, M. (2009). Luxury consumption factors. Journal of Fashion Marketing and Management, 13(2), 231-245. http://dx.doi.org/10.1108/13612020910957734

Jackson, S. L. (2013). Statistics Plain and Simple (Third ed.). Belmont, CA: Wadsworth Cengage Learning.

Jin, B., \& Kang, J. H. (2011). Purchase intention of Chinese consumers towards a US apparel brand: A test of a composite behavior intention model. Journal of Consumer Marketing, 28(3), 187-199. http://dx.doi.org/10.1108/07363761111127617 
Jöreskog, K. G., \& Sörbom, D. (1996). LISREL 8 user's reference guide. Uppsala, Sweden: Scientific Software International.

Kabaskal, H., \& Bodur, M. (2002). Arabic cluster: a bridge between East and West. Journal of World Business, 37(1), 40-54. http://dx.doi.org/10.1016/S10909516(01)00073-6

Kamal, A. A. (1983). Effects of Qatari culture on the development of formal operations. Paper presented at the Annual Meeting of the American Educational Research Association, Montreal, Canada.

Kapferer, J. N. (1997). Managing luxury brands. Journal of Brand Management, 4(4), 251-260. http://dx.doi.org/10.1057/bm.1997.4

Kapferer, J.N., \& Bastien, V. (2009). The specificity of luxury management: turning marketing upside down. Journal of Brand Management, 16(5/6), 311-322. http://dx.doi.org/10.1057/bm.2008.51

Lee, C. (1990). Modifying an American consumer behavior model for consumers in confucian culture: the case of Fishbein behavioral intention model. Journal of International Consumer $\quad$ Marketing, 3(1), 27-50. http://dx.doi.org/10.1300/J046v03n01_03

Lord, K. R., \& Putrevu, S. (2005). Religious influence on consumer behavior: classification and measurement. Advances in Consumer Research, 32, 651-652.

Marciniak, R., \& Mohsen, M. G. (2014). Homogeneity in luxury fashion consumption: an exploration of Arab Women. The Business \& Management Review, 5(1), 3241.

Mason, R. S. (1992). Modeling the demand for status goods. Journal of Consumer Research, 12(3), 341-352.

Miller, D. (1995). Consumption studies as the transformation of anthropology. In D. Miller, Acknowledging Consumption: A Review of New Studies. London: Routledge.

Monkhouse, L., Barnes, B.R., \& Stephan, U. (2011). The influence of face and group orientation on the perception of luxury goods. International Marketing Review, 29(6), 647-72. http://dx.doi.org/10.1108/02651331211277982

Moschis, G. P., \& Moore, R. L. (1979). Decision making among the young: A socialization perspective. Journal of Consumer Research, 6(2), 101-112. http://dx.doi.org/10.1086/208754

Neal, M., Finlay, J. L., Catana, G. A., \& Catana, D. (2007). A comparison of leadership prototypes of Arab and European females. International Journal of Cross Cultural Management, 291-316. http://dx.doi.org/10.1177/1470595807083375 
NFO Merac. (2001). The Arab as consumer 2001. Retrieved from: Www.mediame.com

O'Cass, A., \& Frost, H. (2002). Status brands: examining the effects of non-productrelated brand associations on status and conspicuous consumption. Journal of $\begin{array}{llll}\text { Product } \quad \& \quad \text { Brand } \quad \text { Management, } & \text { 11(2), }\end{array}$ http://dx.doi.org/10.1108/10610420210423455

Pantzalis, I. (1995). Exclusivity strategies in pricing and brand extension. Tucson, Arizona: University of Arizona.

Park, H. J., Rabolt, N., \& Jeon, K. S. (2008). Purchasing global luxury brands among young Korean consumers. Journal of Fashion Marketing and Management, 12(2), 244-259. http://dx.doi.org/10.1108/13612020810874917

Paschyn, C. M. (2013, October 16). Women in the Gulf: better educated but less employed. Al-Fanar Media. Retrieved from: http:/www.alfanarmedia.org/2013/10/women-in-the-gulf-better-educated-but-less-employed/

Riquelme, H. E., Rios, R. E., \& Al-Sharhan, N. (2011). Antecedents of ostentatious consumption in Kuwait. Journal of Islamic Marketing, 2(3), 295-308. http://dx.doi.org/10.1108/17590831111164813

Roux, E. (1995, May). Consumer evaluation of luxury brand extensions. Paper presented at $24^{\text {th }}$ EMAC Annual Conference Proceedings, Cergy-Pontoise, Paris, France.

Sallot, C. A. (2002). What the public thinks about public relations: An impression management experiment. Journalism and Mass Communication Quarterly, 79(1), 150-172. http://dx.doi.org/10.1177/107769900207900111

Seringhaus, R. F. (2002). Cross-cultural exploration of global brands and the internet. Proceedings of the $8^{\text {th }}$ Annual IMP Conference. Dijon: Groupe ESC Dijon Bourgogne.

Sheth, J., Bruce, N., \& Gross, B. I. (1991). Why we buy what we buy: A theory of consumption value. Journal of Business Research, 22(1), 159-170. http://dx.doi.org/10.1016/0148-2963(91)90050-8

Solomon, M. R., Bamossy, G., Askegaard, S., \& Hogg, M. (2010). Consumer behavior: A European perspective. Harlow: Prentice Hall Financial Times.

Steiger, J. H. (1990). Structural model evaluation and modification: An interval estimation approach. Multivariate behavioral research, 25(2), 173-180. http://dx.doi.org/10.1207/s15327906mbr2502_4

Tajfel, H. \& Turner, J. C. (1986). The social identity theory of inter-group behavior. In S. Worchel and L. W. Austin (eds.), Psychology of intergroup relations $\left(2^{\text {nd }}\right.$ ed., pp. 7-24). Chicago: Nelson-Hall 
Teimourpour, B., \& Hanzaee, H. K. (2011). The impact of culture on luxury consumption behavior among Iranian consumer. Journal of Islamic Marketing, 2(3), 309-328.

Triandis, H. (1995). Individualism and Collectivism. Boulder, CO.: Westview Press. http://dx.doi.org/10.1037/10517-066

Tsai, S. (2005). Impact of personal orientation on luxury-brand purchase value: an International investigation. International Journal of Market Research, 47(4), 429-454.

Ullman, J. B. (2001). Structural Equation Modelling. In B. G. Tabachnik \& L.S. Fidell (2001). Using Multivariate Statistics (4th ed.; pp 653-771). Needham Heights, MA: Allyn \& Bacon.

Veblen, T. B. (1899). The Theory of the leisure class: An economic study in the evolution of institutions. New York, NY: MacMillan.

Vel, K., Captain, A., Al Abbas, R., \& Al Hashemi, B. (2011). Luxury buying in the United Arab Emirates. Journal of Business and Behavioral Sciences, 23(3), 145160.

Verhallen, T., \& Robben, H. (1994). Scarcity and preference: an experiment on unavailability and product evaluation. Journal of Economic Psychology, 15(2), 315-331. http://dx.doi.org/10.1016/0167-4870(94)90007-8

Vigneron, F., \& Johnson, L. W. (2004). Measuring perceptions of brand luxury. Journal of Brand Management,11(6), 484-506. http://dx.doi.org/10.1057/palgrave.bm.2540194

Wiedmann, K., Hennigs, N., \& Siebels, A. (2009). Value-based segmentation of luxury consumption behaviour. Psychology and Marketing, 26(7), 625-651.

Yang, C. K (1963). Introduction to the religion of China by Max Weber. New York: Free Press. 


\section{APPENDIX}

\section{Model Fit for the Total Sample}

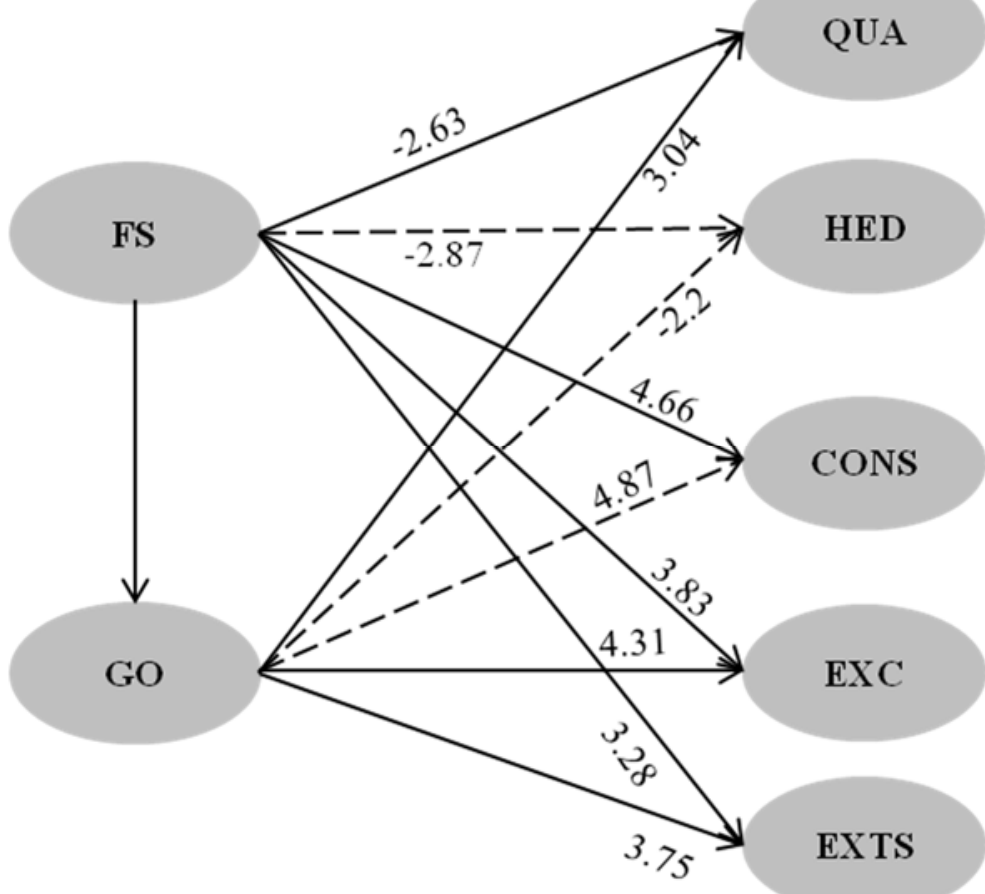

Model Fit for the Sample from the Levant

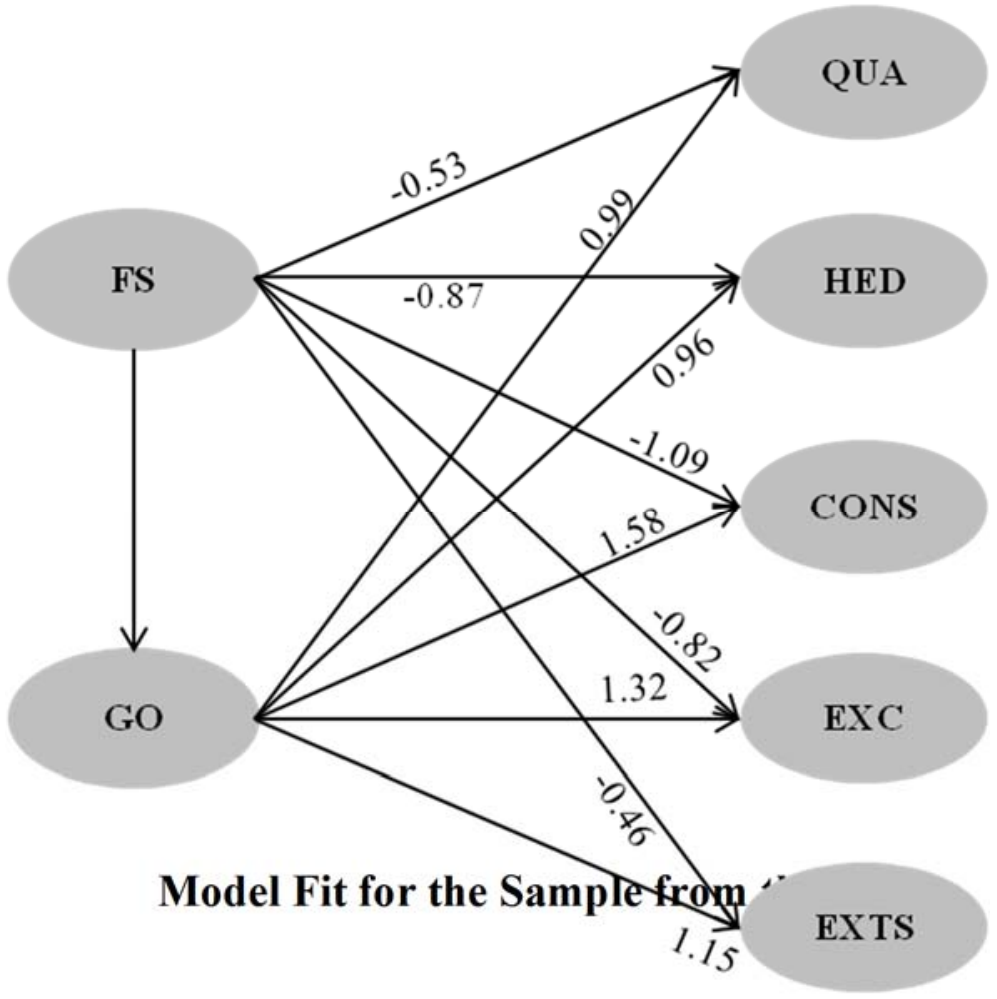




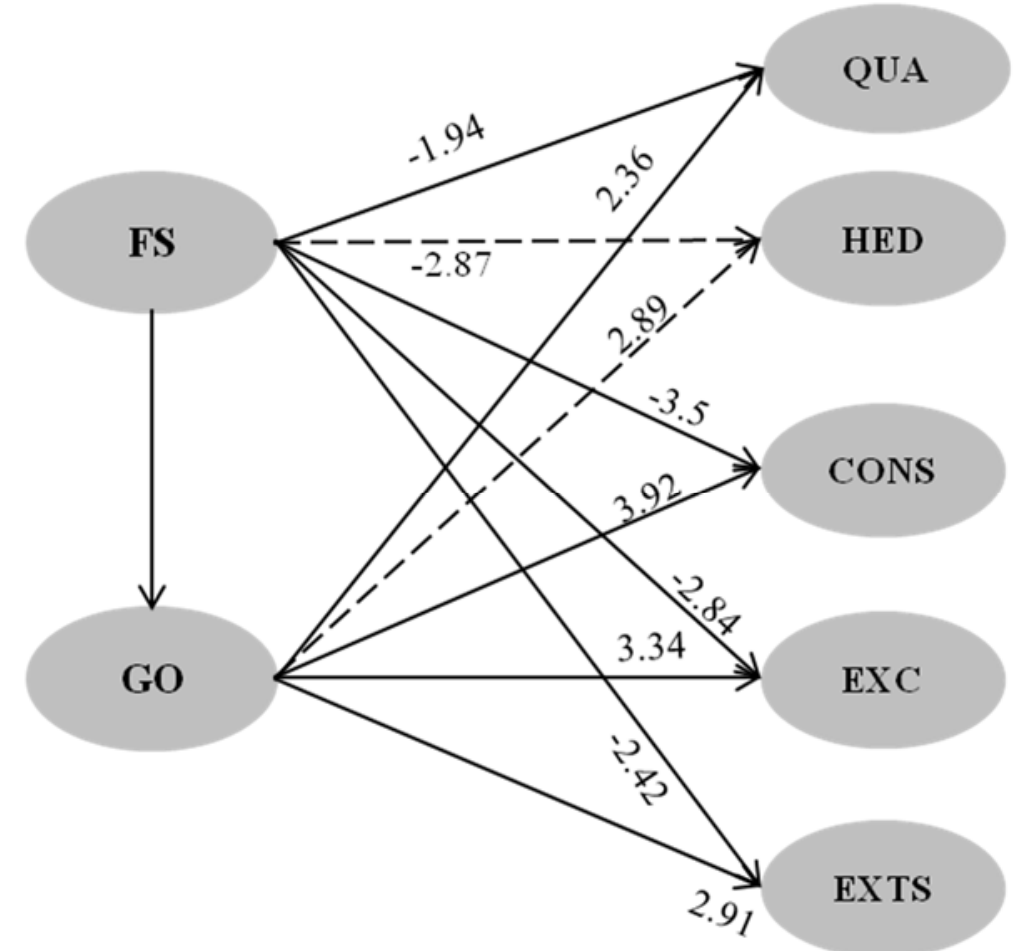

Note: The dotted lines represent the statistically insignificant relations between constructs. 
